Article

\title{
Daily Precipitation Threshold for Rainstorm and Flood Disaster in the Mainland of China: An Economic Loss Perspective
}

\author{
Wenhui Liu ${ }^{1,2}$, Jidong Wu ${ }^{1,2, *}$, Rumei Tang ${ }^{1,2}$, Mengqi Ye ${ }^{1,2}$ and Jing Yang ${ }^{1,2}$ \\ 1 Key Laboratory of Environmental Change and Natural Disaster, Ministry of Education, Beijing Normal \\ University, Beijing 100875, China; lwhtay1996@163.com (W.L.); trm1022@163.com (R.T.); \\ ye_ymq@163.com (M.Y.); yangjing@bnu.edu.cn (J.Y.) \\ 2 Faculty of Geographical Science, Beijing Normal University, Beijing 100875, China \\ * Correspondence: wujidong@bnu.edu.cn; Tel.: +86-10-5880-4647
}

Received: 11 October 2019; Accepted: 1 January 2020; Published: 4 January 2020

\begin{abstract}
Exploring precipitation threshold from an economic loss perspective is critical for rainstorm and flood disaster risk assessment under climate change. Based on the daily gridded precipitation dataset and direct economic losses (DELs) of rainstorm and flood disasters in the mainland of China, this paper first filtered a relatively reasonable disaster-triggering daily precipitation threshold (DDPT) combination according to the relationship between extreme precipitation days and direct economic loss (DEL) rates at province level and then comprehensively analyzed the spatial landscape of DDPT across China. The results show that (1) the daily precipitation determined by the combination of a $10 \mathrm{~mm}$ fixed threshold and 99.3th percentile is recognized as the optimal DDPT of rainstorm and flood disasters, and the correlation coefficient between annual extreme precipitation days and DEL rates reached $0.45(p<0.01)$. (2) The optimal DDPT decreases from southeast (up to $87 \mathrm{~mm}$ ) to northwest $(10 \mathrm{~mm})$ across China, and the DDPTs of 7 out of 31 provinces are lower than $25 \mathrm{~mm}$, while 5 provinces are higher than $50 \mathrm{~mm}$ on average. These results suggest that DDPTs exist with large spatial heterogeneity across China, and adopting regional differentiated DDPT is helpful for conducting effective disaster risk analysis.
\end{abstract}

Keywords: rainstorm and flood disasters; disaster-triggering daily precipitation threshold; extreme precipitation; direct economic losses; China

\section{Introduction}

To effectively predict future flood risk, more and more research has explored the impacts of hydro-climatic extremes on human and economy [1-4], especially in combination with asset exposure and vulnerability [5-7]. In China, many researches have reported that the change trend of total precipitation is not obvious, but the intensity and frequency of extreme precipitation have increased significantly with climate changes [8-11]. Because of obvious regional differences in precipitation and economy, China is particularly vulnerable to the impact of extreme precipitation $[3,12,13]$. For example, according to statistics from the international disaster database (https://www.emdat.be/), the hydrological disaster losses of China reached $\$ 18.9$ billion in 2010, which was two-fifths of the global total. Therefore, reasonable assessment of the intensity and frequency of extreme precipitation is critical for improving our ability to predict rainstorm and flood disaster risk in the future.

Extreme precipitation events are defined as events that exceed the threshold of extreme precipitation and have a significant impact on human society [14]. The basis and key to assess the intensity and frequency of extreme precipitation is to determine the disaster-triggering daily precipitation threshold 
(DDPT) [15]. Currently, there is no uniform threshold standard for the determination of extreme precipitation events [16]. There are various methods for determining the extreme precipitation globally, including fixed threshold method, parametric method, non-parametric method, and detrended fluctuation analysis method [14-18]. The fixed threshold method uses an absolute daily precipitation intensity as the critical value of the region [14]. For example, precipitation exceeding $50 \mathrm{~mm}$ over $24 \mathrm{~h}$ is usually defined as extreme precipitation in China $[16,19]$. This method is suitable for small-scale areas and has strong subjectivity and experience [20-22].

The most commonly used nonparametric method is the percentile method, which ranks the amount of precipitation over a certain period of time and selects a certain percentile daily precipitation value as the extreme precipitation criterion for the region [23]. The percentiles selected varied from study to study. Zhai et al. [24] considered the 95th percentile of all rain days during 1961-1990 as the criterion for judging extreme precipitation events. Beniston et al. [25] and Pielke et al. [2] regarded 90th percentile of the observed precipitation data as a standard of extreme precipitation events. This method is suitable for the definition and comparison of extreme precipitation events in different regions [26,27]. Parametric methods include probabilistic analysis [28], the peak over threshold (POT) method [16], the generalized extreme value distribution (GEV) method [29]. These parametric methods depend on the size of the data series and the probability distribution, which could greatly affect the results [22].

As a key criterion used to define the intensity of disaster-triggering factors, the DDPT is closely related to the occurrence of disasters [16]. Precipitation above the DDPT is likely to have a negative impact on social and economic development [14]. From the perspective of the rainstorm and flood disasters occurrence mechanism [30], the methods determine the extreme precipitation threshold only by statistical characteristics of precipitation that is separate from whether extreme precipitation causes negative economic and social influences, which could mislead rainstorm and flood disaster risk assessment because it ignores the vulnerability factors of human and economy in determining a disaster. Therefore, the determination of the DDPT should combine the economic losses caused by precipitation and comprehensively consider the relationships among hazard, exposure of socioeconomics, and disaster losses. In this way, we could determine the optimal DDPT that is most likely to cause disaster loss from a practical point of view, namely, the threshold of disaster-triggering precipitation, i.e., the DDPT. In addition, the current research on the DDPT in China mainly focuses on a small-scale range of regions and basins [31-37].

To improve these imperfections, there are two main aims of this study: (1) To explore the disaster-triggering threshold of extreme precipitation in the mainland of China from an economic loss perspective, and (2) to comprehensively analyze the spatial landscape and statistical characteristics of the DDPT across China at regional and provincial scales (see Figure 1). Therefore, based on the daily gridded observational precipitation dataset (1961-2012) and rainstorm and flood disaster direct economic losses (DELs) (2004-2012) in the mainland of China, this study established a large number of threshold combinations by combining the fixed threshold method and percentile method, which are commonly used to determine the disaster-triggering precipitation threshold value. Then, we extracted the corresponding rainstorm and flood hazard areas and further explored the correlation between extreme precipitation days and DEL rates in different combinations to determine a more reasonable DDPT across China. The optimal DDPT based on the disaster mechanism (hazard, exposure) helps provide a basis for risk assessment and management of rainstorm and flood disasters. 


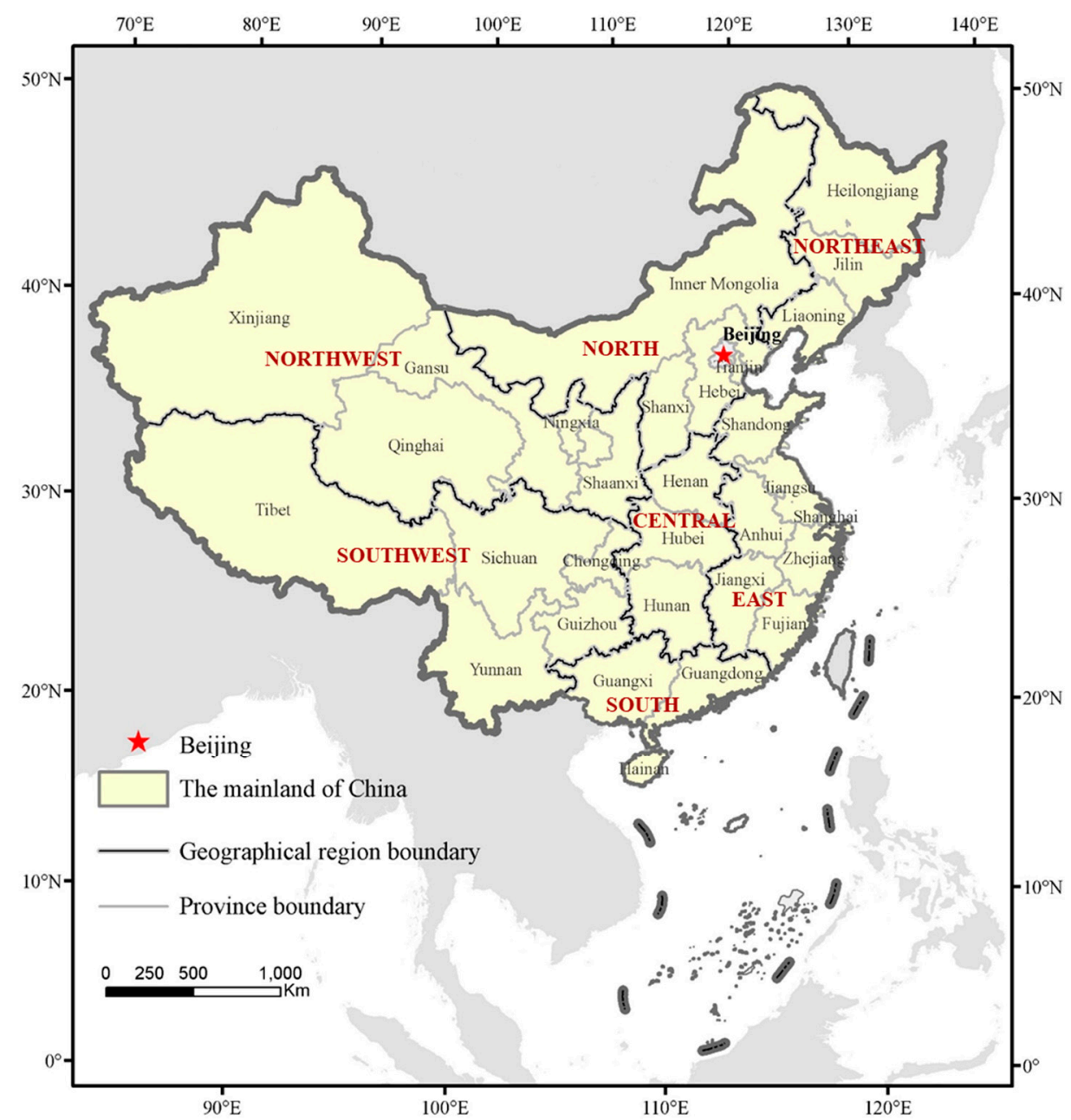

Figure 1. Seven geographical divisions and 31 provinces in the mainland of China.

\section{Data and Methods}

\subsection{Data Sources}

Four main datasets were used to analyze the disaster-triggering precipitation threshold of rainstorm and flood disasters (see Table 1). First, an interpolated gridded observational precipitation dataset (CN05.1) from 1961 to 2012 was generated by Wu and Gao [38] based on 2400 observational stations in China. This dataset indicates similar rainfall frequency distributions as that of the station dataset [19] and has been widely used in precipitation change studies over China [39,40]. This study considers a daily precipitation value greater than or equal to $0.1 \mathrm{~mm}$ as an effective precipitation value [41,42].

Second, the annual provincial DELs of rainstorm and flood disasters in the mainland of China were obtained from China's Yearbook of Meteorological Disasters [43]. DELs caused by landfall typhoons were also included. These data were used to compute the DEL rate of rainstorm and flood disasters as vulnerability indicators [44].

Third, the asset value map of China in 2015 is 30 arc-second resolution and offers a quick and accurate assessment of economic exposure [44-46]. This map was used to evaluate the asset value exposure in rainstorm and flood hazard areas [44,47].

Finally, the consumer price index (CPI) and price indices of investment in fixed assets were respectively used to adjust the DELs and asset values to the price level of $2012[47,48]$. 
Table 1. Data sources and description.

\begin{tabular}{cccc}
\hline Data Name & Resolution & Time Periods & Source \\
\hline $\begin{array}{c}\text { Gridded observational } \\
\text { precipitation dataset of China } \\
\text { (CN05.1) }\end{array}$ & $0.25^{\circ} \times 0.25^{\circ}$, daily & $1961-2012$ & Wu and Gao [38] \\
\hline $\begin{array}{c}\text { Direct economic losses of } \\
\text { rainstorm and flood disasters }\end{array}$ & Provincial level of China & $2004-2012$ & $\begin{array}{c}\text { China Meteorological } \\
\text { Administration (CMA) [43] }\end{array}$ \\
\hline Asset value map of China & 30 arc second & 2015 & Wu et al. [44] \\
\hline $\begin{array}{c}\text { Consumer price index } \\
\text { Price indices of investment in } \\
\text { fixed assets }\end{array}$ & Provincial level of China & 2004-2012 & $\begin{array}{c}\text { National Bureau of } \\
\text { Www.stats.gov.cn) }\end{array}$ \\
\hline
\end{tabular}

\subsection{Methods}

To more reasonably determine the DDPT in China, this study divided the methodology into four parts (see Figure 2). First, we combined the percentile method with a fixed threshold method to build a series of alternative DDPT value of daily extreme precipitation. Then we extracted the rainstorm and flood hazard areas for each DDPT value. Third, we calculated the annual provincial rainstorm and flood extreme precipitation index and annual provincial DEL rate of different DDPT combinations. Finally, we screened DDPT value combinations and selected the most reasonable one by calculating the correlation between the extreme precipitation index and DEL rate.

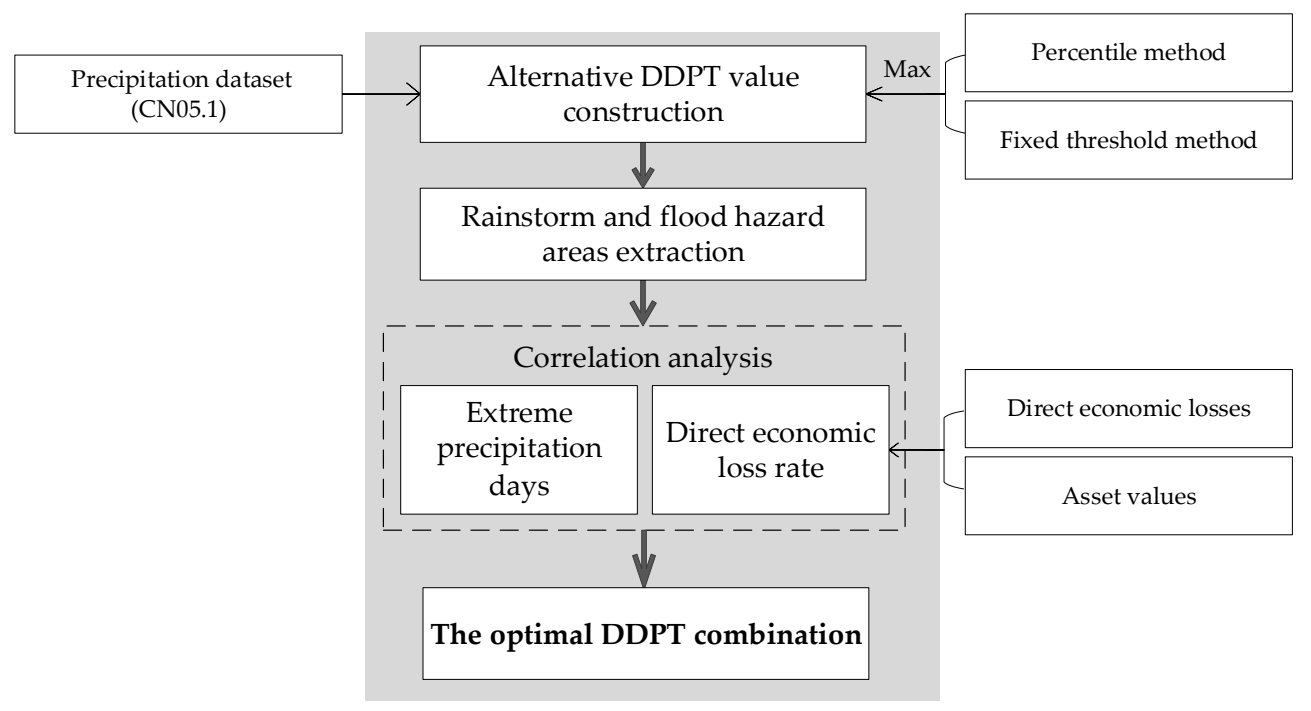

Figure 2. The optimal disaster-triggering daily precipitation threshold (DDPT) value determination framework.

\subsubsection{Alternative DDPT Value Construction}

The percentile method is widely used in determining the extreme precipitation threshold globally [23], and 90\%, 95\%, 99\% are common percentiles [2,23-25]. This study first selected $90.0-99.9 \%$ $(0.1 \%$ intervals) as the selection range of DDPT. After checking the observed daily precipitation data in the extremely dry area of the northwestern China, the DDPT value determined by the percentile method was lower than $5 \mathrm{~mm}$, which is not consistent with the fact that the DDPT in the recorded disaster event for this area should be higher than $5 \mathrm{~mm}$ [32-34]. As such, we further selected $5 \mathrm{~mm}$ as the minimum extreme precipitation threshold value and gradually increased ( $1 \mathrm{~mm}$ intervals) it to 
determine a DDPT value. That is, both the percentile method and the fixed threshold method are used to constitute a threshold combination. Finally, for each threshold combination, an alternative DDPT value can be determined by taking the maximum of both.

\subsubsection{Rainstorm and Flood Hazard Area Extraction}

How to effectively determine the rainstorm and flood hazard areas is the key to calculating the asset value exposure. First, for each day, based on each alternative DDPT value and the CN05.1 dataset, the grids with precipitation values equal to or greater than this DDPT value can be extracted, which is defined as the daily rainstorm and flood hazard area. Second, for each year, the affected extent that may experience damage from rainstorm and flood disasters can be acquired from merging daily rainstorm and flood hazard areas. Moreover, for each grid, the extreme precipitation days, which are defined as the days with daily precipitation that is equal to or greater than the precipitation threshold, can be calculated based on the extracted rainstorm and flood hazard areas.

\subsubsection{Optimal DDPT Selection}

The optimal DDPT is selected based on the correlativity between the annual extreme precipitation days and annual DEL rates at the province level.

First, considering the incomparability of absolute thresholds between different provinces, this study used the number of annual extreme precipitation days (d) to characterize the magnitude of the disaster-triggering precipitation at the provincial level. Province-level annual extreme precipitation days are defined as the average annual extreme precipitation days within the merged daily rainstorm and flood hazard areas.

Second, the accumulated asset value located in the yearly rainstorm and flood hazard areas is defined as the economic exposure to annual rainstorm and flood disasters, and the province-level DEL rate is calculated by the DELs caused by rainstorm and flood disasters divided by the economic exposure in the same year. To estimate the province-level annual economic exposure, this study generates gridded annual asset value maps in the periods of 2004-2012 by employing an average annual growth rate of the asset value [48], which is $14 \%$, based on the asset value map of China in 2015 [44]. We aggregated asset value maps $\left(30^{\prime \prime} \times 30^{\prime \prime}\right)$ into the same spatial resolution of CN05.1 as rainstorm and flood hazard areas $\left(0.25^{\circ} \times 0.25^{\circ}\right)$. Then, we overlaid the rainstorm and flood hazard areas on the asset value maps to extract the exposed asset values for each year. Considering inflation, we adjusted DELs and asset value to the price level of 2012 using CPI and price indices of investments in fixed assets, respectively [46,47].

Third, based on the hazard frequency (i.e., extreme precipitation days) and vulnerability (i.e., DEL rate) of rainstorm and flood disasters by province and by year, the optimal DDPT can be determined when the highest correlation coefficient exist between the extreme precipitation days and DEL rates.

Finally, based on the determined optimal DDPT, the spatial distribution of the DDPT value were described at the regional and provincial levels.

\section{Results}

\subsection{The Correlation between Extreme Precipitation Days and DEL Rates}

As shown in Figure 3, the correlation between extreme precipitation days and DEL rates of rainstorm and flood disasters changed significantly with the change in the combination of percentile and fixed precipitation threshold value at the provincial level in China. Note that rainstorm and flood hazard areas are zero in some years in individual provinces, if the percentile is over $99.5 \%$ or the fixed precipitation threshold is equal to or greater than $20 \mathrm{~mm}$, which is not consistent with the actual disaster damage records in the period of 2004-2012. 


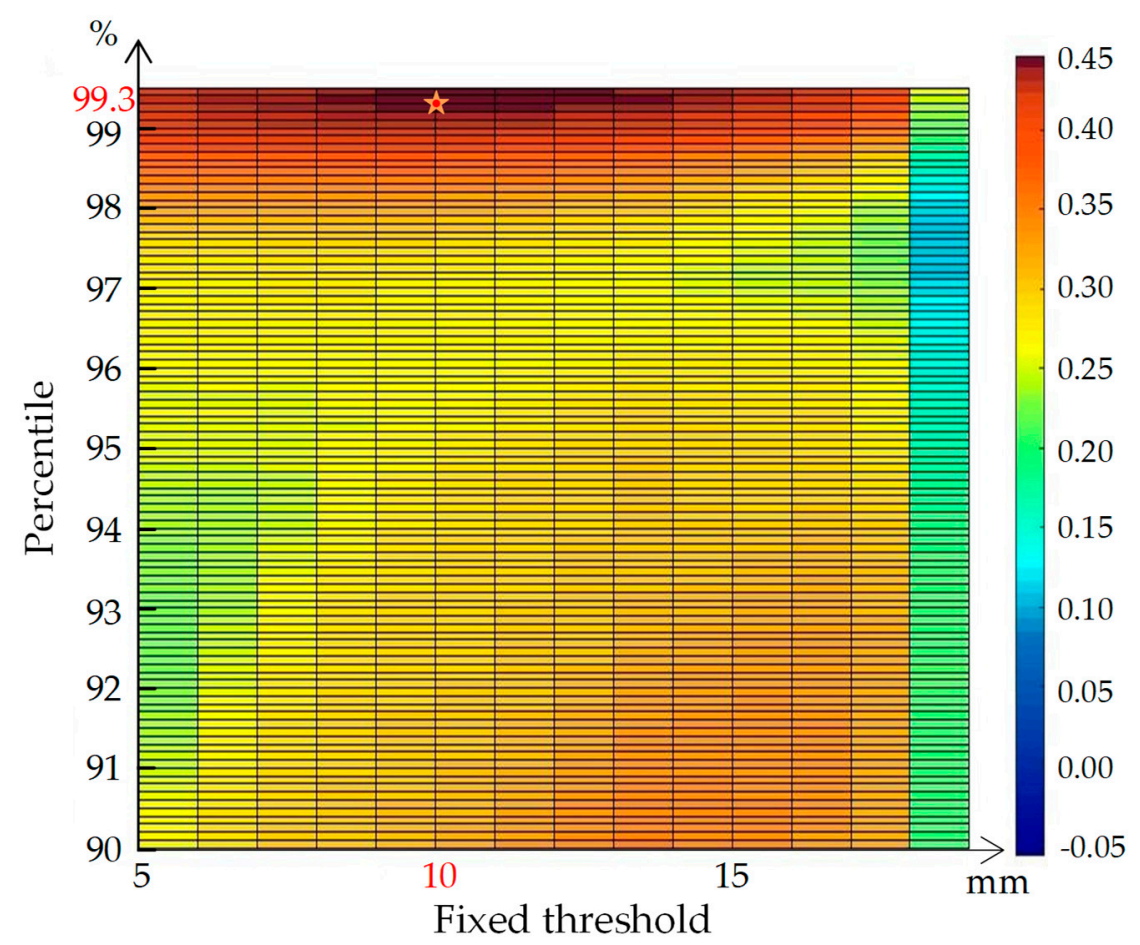

Figure 3. The correlation coefficient $(n=279)$ between the extreme precipitation days and the direct economic losses (DEL) rates of rainstorm and flood disasters under different daily precipitation threshold combinations at the provincial level in the period of 2004-2012 in China.

When the initial fixed precipitation threshold value is constant, as the percentile value increases, the correlation coefficient between annual extreme precipitation days (D) and DEL rates first decreases and then increases, and the maximum value is $99.3 \%$ when the initial absolute daily precipitation threshold changes from $5 \mathrm{~mm}$ to $19 \mathrm{~mm}$ by a $1-\mathrm{mm}$ interval. When the percentile value is $99.3 \%$, with the increase in the initial daily precipitation threshold value, the correlation coefficient first increases and then decreases sharply, and the maximum correlation coefficient value is about 0.45 $(n=279, p<0.01)$ at the $10 \mathrm{~mm}$ initial daily precipitation threshold. Therefore, the combination of the 99.3th percentile and $10 \mathrm{~mm}$ initial daily precipitation threshold was selected as the most optimal threshold combination for rainstorm and flood disasters.

\subsection{Annual Relationship between Extreme Precipitation Days and DEL Rates Determined by Rainstorm and Flood Hazard Area under the Optimal DDPT}

To verify the validity of the optimal DDPT in determining the relationship between extreme precipitation days and DEL rates, we further show this relationship for each year. As can be seen in Figure 4, the spatial distribution of rainstorm and flood hazard areas and of extreme precipitation days vary between years (see Figure 4). The extreme precipitation center determined by the optimal DDPT could be in coastal Southeast China (see Figure $4 b, c, e, f)$, in the inland area of South China region (see Figure $4 \mathrm{~g}$ ), in the northern part of North China (see Figure $4 \mathrm{a}, \mathrm{e}, \mathrm{i}$ ), and in the center of Southwest China (see Figure $4 \mathrm{~h}$ ).

Moreover, the relationship between the extreme precipitation days and DEL rates varies between years, but the DEL rates increases with extreme precipitation days at the province level. Among the 9 years from 2004 to 2012, the DEL rates increased significantly $(p<0.01)$ with the number of average extreme precipitation days for the five years (see Figure $4 b, c, e, g, h$ ), especially when the correlation coefficient of 2006 reached $0.8128(n=31, p<0.01)$ (Figure 4c). In the other years, the DEL rates increased non-significantly with the number of extreme precipitation average days (see Figure $4 \mathrm{a}, \mathrm{d}, \mathrm{f}, \mathrm{i}$ ). 
In general, there is a positive correlation between the annual DEL rates and the number of annual extreme precipitation days, although this positive correlation is not significant in some years.

(a) 2004

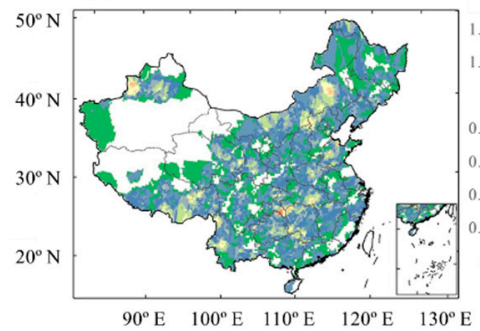

(c) 2006

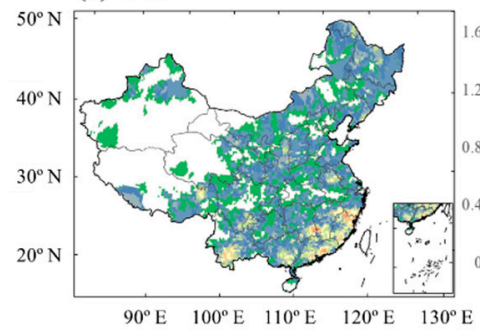

(e) 2008

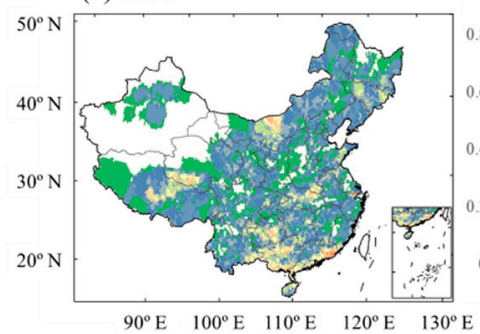

(g) 2010

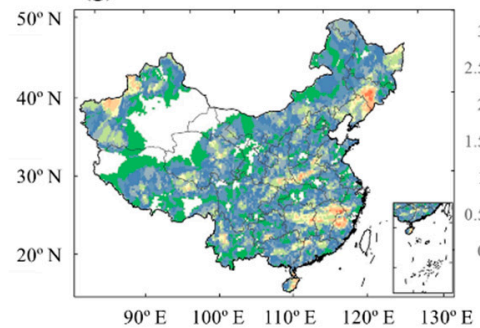

(i) 2012

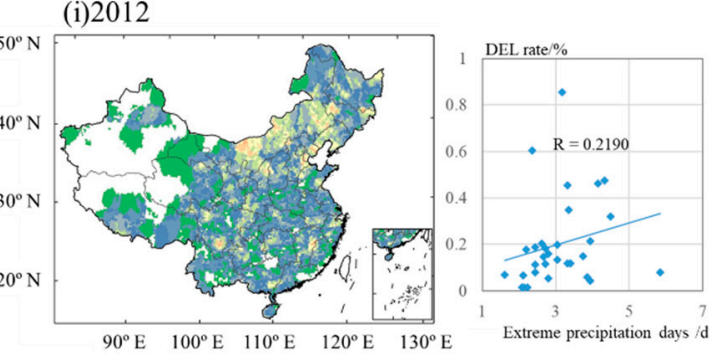

(b) 2005
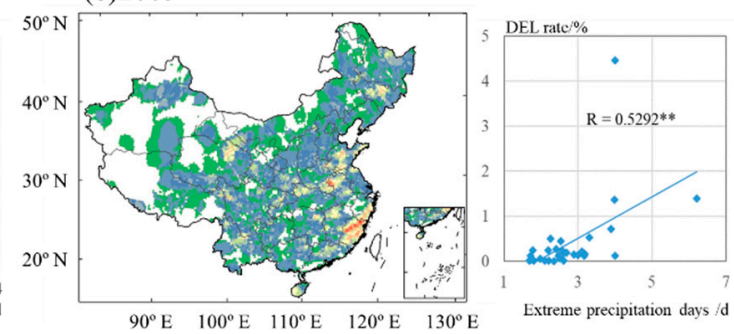

(d) 2007

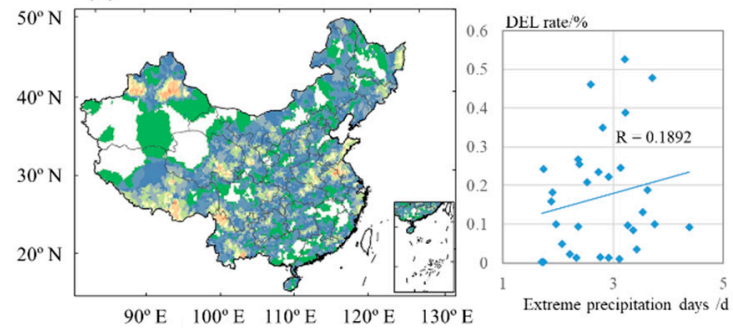

(f) 2009

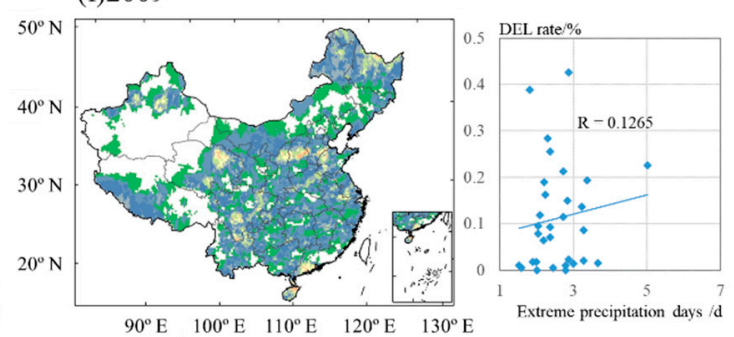

(h) 2011

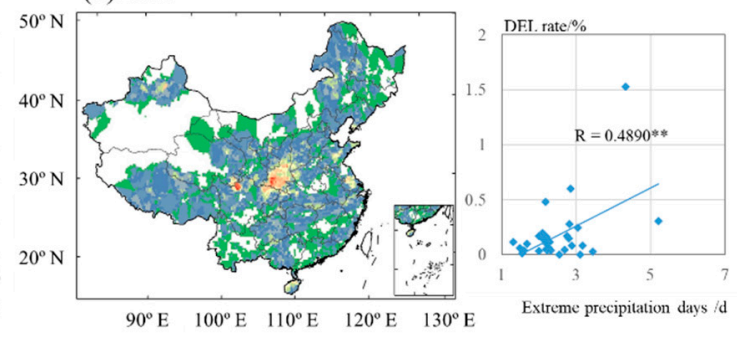

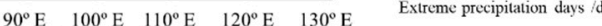

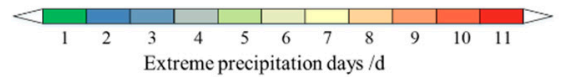

Figure 4. The annual correlation (** significant at the 0.01 level.) between the extreme precipitation days and the DEL rates of rainstorm and flood disasters at the province level from 2004 to 2012 (a-i) under the optimal DDPT in the mainland of China. For each year, extreme precipitation days equal the sum of extreme precipitation days of grids divided by the total number of grids within the merged daily rainstorm and flood hazard areas within a province. 


\subsection{Spatial Distribution of Disaster-Triggering Daily Precipitation Threshold}

The spatial distribution of DDPTs across China is shown in Figure 5a. The DDPTs show a decreasing distribution from the southeastern coast to the northwestern inland of China, and the boundary of the adjacent threshold is clear, showing a trend from northeast to southwest. The maximum DDPT value is distributed in the coastal southern China region, at approximately $87 \mathrm{~mm}$, and the northwestern inland region has the minimum DDPT value, which is $10 \mathrm{~mm}$. Note that most threshold values of northwestern inland China are less than $20 \mathrm{~mm}$, that is, the fixed precipitation threshold has an influence on the northwestern inland region, and the percentile method works elsewhere.

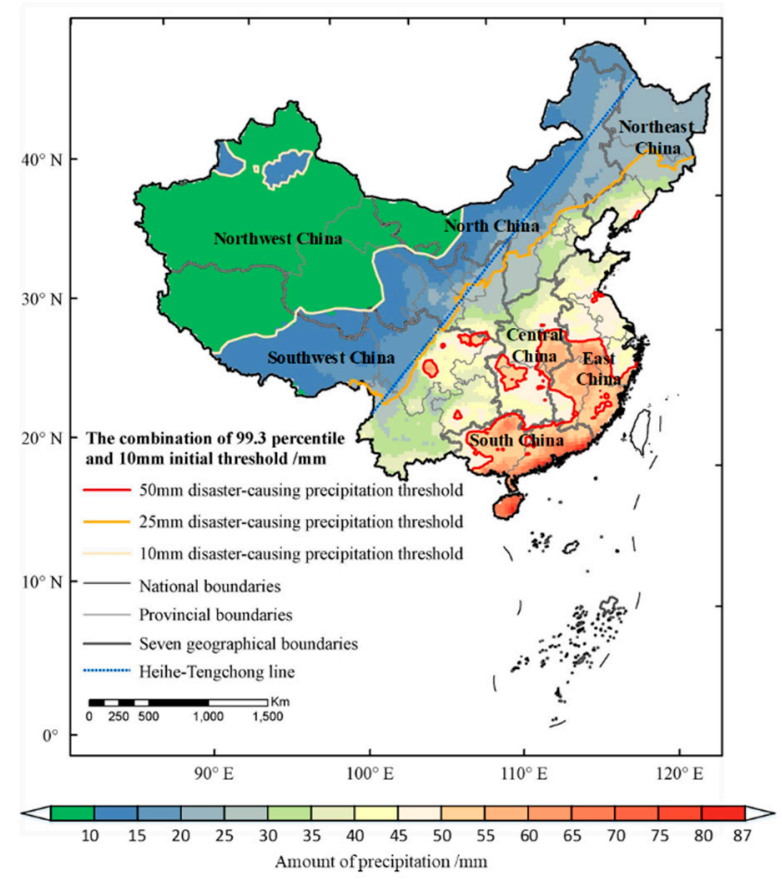

(a)

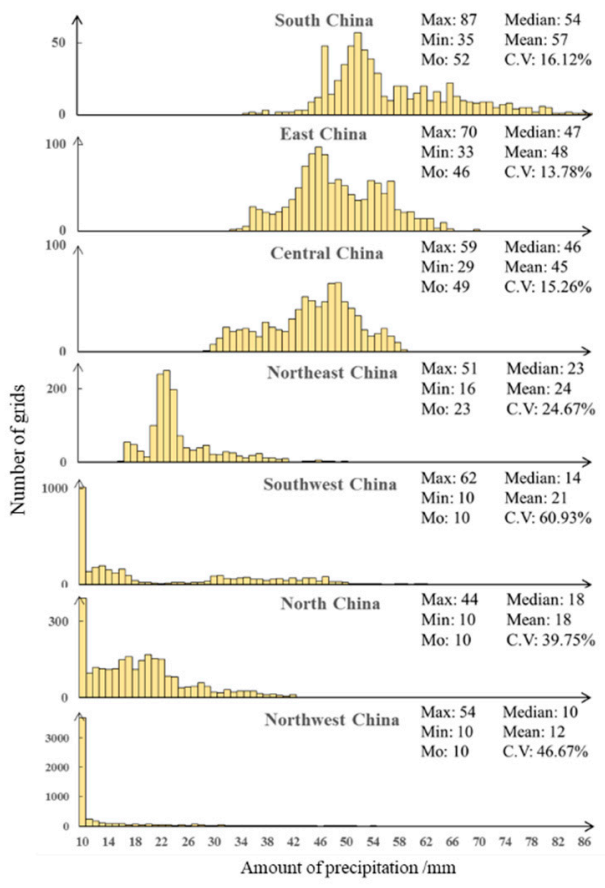

(b)

Figure 5. Spatial distribution of the DDPT (a) and its precipitation intensity frequency in seven geographic regions of China $(\mathbf{b})$.

From the perspective of the spatial DDPT contour (see Figure 5a, Table 2), approximately $66 \%$ of the DDPTs in the mainland of China are less than $25 \mathrm{~mm}$; that is, the DDPTs in these areas are only light rain or moderate rain, according to the precipitation intensity classification in China [16], and approximately one-quarter of the country meets the threshold for large rain. Only $8.3 \%$ of the country's DDPT exceeds $50 \mathrm{~mm}$, reaching the level of heavy rain. Moreover, the Heihe-Tengchong line, which roughly coincides with the $400 \mathrm{~mm}$ annual precipitation contour and is also regarded as the dividing line between economically developed areas (east of the line) and underdeveloped areas (west of the line) in the mainland of China [49,50], is approximately located near the contour line of the 25-mm DDPT.

At the geographical regional level, Figure $5 b$ shows the DDPT frequency distribution of 7 geographical divisions, and each region has a unique statistical characteristic of its threshold distribution. The average DDPTs of South China, East China, Central China, Northeast China, Southwest China, North China, and Northwest China are $57 \mathrm{~mm}, 48 \mathrm{~mm}, 45 \mathrm{~mm}, 24 \mathrm{~mm}, 21 \mathrm{~mm}, 18 \mathrm{~mm}$, and $12 \mathrm{~mm}$, respectively, and the value in South China is 4.75 times that of the value in Northwest China. In addition, in terms of the coefficient of variation (CV) and regional uniformity, the mean DDPT distribution of South China, East China, and Central China is relatively uniform, while that in Northwest and Southwest China is relatively discrete. 
Table 2. The precipitation intensity classification in China [16] and the corresponding area distribution percentage of different levels of DDPTs.

\begin{tabular}{ccc}
\hline Grade of Daily Precipitation & Daily Precipitation $\mathbf{( m m )}$ & $\begin{array}{c}\text { Area Distribution Percentage of Daily } \\
\text { Precipitation Threshold in China }\end{array}$ \\
\hline Light rain & $<10.0 \mathrm{~mm}$ & 0 \\
Moderate rain & $10.0 \sim 24.9 \mathrm{~mm}$ & $66.0 \%$ \\
Large rain & $25.0 \sim 49.9 \mathrm{~mm}$ & $25.7 \%$ \\
Heavy rain & $50.0 \sim 99.9 \mathrm{~mm}$ & $8.3 \%$ \\
Very heavy rain & $100.0 \sim 249.9 \mathrm{~mm}$ & 0 \\
\hline
\end{tabular}

At the province level (Table 3), the statistical value of the DDPT of most provinces across China is between $25 \mathrm{~mm}$ and $50 \mathrm{~mm}$, and the regions with a relatively large dispersion of DDPT values are mainly consistent with the provinces with low DDPTs. There are 7 provinces with mean DDPTs lower than $25 \mathrm{~mm}$ : Xinjiang, Qinghai, Tibet, Gansu, Inner Mongolia, Ningxia, and Heilongjiang. Xinjiang, Qinghai, Tibet and Gansu, and Inner Mongolia have the lowest DDPTs (approximately $10 \mathrm{~mm}$ ). Guangxi, Jiangxi, Fujian, Guangdong, and Hainan have mean DDPTs values higher than $50 \mathrm{~mm}$, among which Hainan has the highest mean DDPT value (about $71 \mathrm{~mm}$ ) and Guangdong has the maximum DDPT value (about $87 \mathrm{~mm}$ ). The remaining provinces have mean DDPT values between $25 \mathrm{~mm}$ and $50 \mathrm{~mm}$. Additionally, most provinces have CV values below 20\%, except for Gansu, Sichuan, Inner Mongolia, Ningxia, Shaanxi, and Hebei.

Table 3. Statistical DDPT values in 31 provinces of the mainland of China. Province-level DDPT values are calculated based on an average value of the gridded DDPT values within a province.

\begin{tabular}{|c|c|c|c|c|c|c|c|}
\hline \multirow{2}{*}{$\begin{array}{l}\text { Disaster-Triggering } \\
\text { Daily Precipitation } \\
\text { Threshold (mm) }\end{array}$} & \multirow{2}{*}{$\begin{array}{c}\text { Province } \\
\text { (Sub-National) }\end{array}$} & \multicolumn{6}{|c|}{ Statistical DDPT Values } \\
\hline & & $\begin{array}{l}\text { Median } \\
(\mathrm{mm})\end{array}$ & $\begin{array}{l}\text { Min } \\
(\mathrm{mm})\end{array}$ & $\begin{array}{l}\text { Max } \\
(\mathrm{mm})\end{array}$ & $\begin{array}{c}\text { Mo } \\
(\mathrm{mm})\end{array}$ & $\begin{array}{l}\text { Mean } \\
(\mathrm{mm})\end{array}$ & $\begin{array}{l}\text { CV } \\
(\%)\end{array}$ \\
\hline \multirow{7}{*}{$\mathrm{DDPT}<25 \mathrm{~mm}$} & Xinjiang & 10 & 10 & 15 & 10 & 10 & 4 \\
\hline & Qinghai & 10 & 10 & 18 & 10 & 11 & 15 \\
\hline & Tibet & 10 & 10 & 23 & 10 & 11 & 18 \\
\hline & Gansu & 10 & 10 & 35 & 10 & 15 & 40 \\
\hline & $\begin{array}{c}\text { Inner } \\
\text { Mongolia }\end{array}$ & 15 & 10 & 28 & 10 & 16 & 28 \\
\hline & Ningxia & 15 & 11 & 26 & 13 & 16 & 26 \\
\hline & Heilongjiang & 22 & 16 & 25 & 23 & 21 & 10 \\
\hline \multirow{19}{*}{$\begin{array}{c}25 \mathrm{~mm} \leq \mathrm{DDPT} \leq 50 \\
\mathrm{~mm}\end{array}$} & Shanxi & 26 & 19 & 32 & 28 & 26 & 11 \\
\hline & Jilin & 25 & 20 & 40 & 25 & 26 & 15 \\
\hline & Sichuan & 26 & 10 & 62 & 16 & 29 & 48 \\
\hline & Shaanxi & 28 & 17 & 53 & 27 & 29 & 25 \\
\hline & Hebei & 32 & 17 & 44 & 32 & 30 & 24 \\
\hline & Yunnan & 31 & 16 & 44 & 30 & 32 & 14 \\
\hline & Beijing & 34 & 24 & 41 & 33 & 35 & 13 \\
\hline & Liaoning & 35 & 22 & 51 & 32 & 35 & 18 \\
\hline & Tianjin & 37 & 34 & 40 & 37 & 37 & 5 \\
\hline & Henan & 40 & 29 & 54 & 37 & 40 & 16 \\
\hline & Guizhou & 41 & 26 & 51 & 44 & 40 & 13 \\
\hline & Shandong & 40 & 33 & 49 & 37 & 40 & 9 \\
\hline & Chongqing & 42 & 35 & 52 & 41 & 42 & 8 \\
\hline & Shanghai & 45 & 41 & 46 & 45 & 44 & 4 \\
\hline & Hubei & 47 & 31 & 59 & 56 & 46 & 17 \\
\hline & Jiangsu & 46 & 40 & 50 & 46 & 46 & 5 \\
\hline & Hunan & 48 & 40 & 57 & 48 & 47 & 6 \\
\hline & Zhejiang & 46 & 41 & 62 & 44 & 48 & 11 \\
\hline & Anhui & 46 & 41 & 65 & 46 & 49 & 13 \\
\hline \multirow{5}{*}{$\mathrm{DDPT}>50 \mathrm{~mm}$} & Guangxi & 52 & 35 & 76 & 52 & 52 & 12 \\
\hline & Jiangxi & 54 & 43 & 65 & 55 & 53 & 9 \\
\hline & Fujian & 54 & 48 & 70 & 54 & 54 & 6 \\
\hline & Guangdong & 61 & 47 & 87 & 53 & 61 & 16 \\
\hline & Hainan & 71 & 65 & 81 & 67 & 71 & 6 \\
\hline
\end{tabular}




\section{Discussion}

\subsection{Importance of Exploring Optimal DDPT from An Economic Loss Perspective}

Based on the perspective of whether precipitation has adverse consequences to the economy and society, we comprehensively determined the optimal DDPT value according to the correlation between extreme precipitation frequency and corresponding rainstorm and flood disaster DEL rate at province scale. First, different from traditional extreme precipitation determination methods $[17,18,20,21]$, which mainly consider the extreme nature of precipitation itself, the method presented in this study determines DDPTs based on the link between extreme precipitation and adverse disaster impacts. The optimal DDPTs could provide a practical reference to recognize the impact and define the warning criteria of extreme precipitation events from the disaster risk perspective. For example, according to a continuous disaster-triggering rainstorm in Sichuan Province in June 2013 recorded by Wang et al. [51], the daily precipitation value of $26.9 \mathrm{~mm}$ can also cause disaster losses, and this value is close to the median precipitation value $(26.0 \mathrm{~mm})$ of the DDPT in Sichuan Province determined by this paper.

\subsection{Advantages of Combining Percentile Method and Fixed Threshold Method to Determine DDPT}

Previous studies had used the percentile method and fixed threshold method for rainstorm and flood disaster risk assessment [16,19,23-25], while both methods have its advantages and disadvantages. The fixed threshold method is suitable for local scale extreme precipitation analysis. While the percentile method could consider regional differentiation of precipitation background values, and can be used in global scale extreme precipitation analysis, while considering precipitation-induced disaster, the extreme precipitation value determined by this method could be noneffective in the extreme arid region as demonstrated above in Xinjiang province. As such, we determine DDPT value using a combination of the percentile method and fixed threshold value, which could determine the optimal DDPT in large scale and also avoid occurrence of noneffective DDPT value.

\subsection{The Spatial Heterogeneity and Regional Complexity of DDPT}

The DDPT has strong spatial heterogeneity and regional complexity (Figure 5 and Table 3). Concretely, the average DDPT value of $57 \mathrm{~mm}$ in South China may lead to rainstorm and flood disasters, while the value of $10 \mathrm{~mm}$ in Northwest China may also lead to rainstorm and flood disasters; these values are closely related to climatic conditions, precipitation types, topography and geomorphology, and social and economic activities. Additionally, the CV of the DDPT could indicate the degree of dispersion in different regions, which indirectly indicates the complexity of the DDPT within a region [30,52]. As shown in Figure 5 and Table 3, 6 provinces that cross multiple threshold isolines and are near the Heihe-Tengchong line (Gansu, Sichuan, Inner Mongolia, Ningxia, Shaanxi, and Hebei) have CV values greater than $20 \%$. However, provinces distributed in the eastern coastal and northwestern inland regions (e.g., Shanghai, Tianjin, Jiangsu, Hainan, Fujian and Shandong, and Xinjiang) have relatively low $\mathrm{CV}$ values, indicating that the spatial distribution of the DDPT is relatively homogeneous in these provinces.

Therefore, combined with the precipitation classification standard formulated by the national meteorological department, this study helps with the implementation of disaster warning and risk analysis by exploring the relationship between disaster consequences and extreme precipitation intensity and provides a basis for disaster possibility forecasting from regional or provincial scales.

\subsection{Limitations}

Some limitations exist in the determined DDPT values across the mainland of China. First, although this study is based on the high-resolution daily gridded observational dataset (CN05.1) generated from more than 2400 meteorological stations by the China Meteorological Administration to determine the DDPT, the analysis of precipitation on an hourly scale may be more closely related to the actual disaster than the daily precipitation data that were used here. The short-term heavy 
precipitation of $16.0 \mathrm{~mm}$ can also cause disaster losses, according to previous records about the major heavy precipitation process in Beijing from June to August 2011 [53]. Second, compared with the gridded precipitation and asset value datasets, the provincial DELs caused by rainstorm and flood disasters in this paper are relatively coarse. Acquiring rainstorm and flood disaster event-level DELs will be helpful for further improving the reliability of the determination of DDPT based on this research's idea. Third, based on the regional disaster system theory $[1,30]$, the occurrence of rainstorm and flood disasters is related not only to precipitation intensity and exposed assets but also to the topography and protective measures [43]. The optimal DDPT values just represent an average state of regional or provincial disaster-triggering precipitation threshold, which may be not coincide with the actual local DDPT but it is the DDPT value most likely to cause disaster at the provincial level. As a result, the DDPT results estimated here may be misleading to rainstorm and flood disaster warning at the micro scale, necessary verification by disaster event investigation in the future is critical to improve its reliability.

\section{Conclusions}

Determining the extreme precipitation threshold is the basis of exploring extreme precipitation events, but determining the DDPT is a challenging issue. Based on the daily gridded precipitation dataset (1961-2012) and annual province-level DELs of rainstorm and flood disasters (2004-2012) in the mainland of China, this study found that the optimal rainstorm and flood DDPT is the combination of the $10 \mathrm{~mm}$ fixed threshold and the 99.3th percentile of daily precipitation. It has the highest correlation coefficient between annual extreme precipitation days determined by the optimal DDPT and rainstorm and flood disaster DEL rate at the province level, which is about $0.45(p<0.01)$. Meanwhile, the rainstorm and flood disaster DEL rates increased with the number of annual extreme precipitation days.

In addition, the spatial distribution of the DDPT values decreases from the southeastern coast to the northwestern inland area across China, and adjacent threshold isolines generally show a trend from northeast to southwest. The optimal rainstorm and flood DDPT values at the regional and provincial levels have strong spatial heterogeneity. At the regional level, the DDPT values of most areas of Northwest China, North China, Southwest China, and Northeast China were less than $25 \mathrm{~mm}$, while the DDPT value in South China was more than $50 \mathrm{~mm}$. At the province level, there were 7 provinces with DDPTs lower than $25 \mathrm{~mm}$, while the DDPTs of 5 provinces were higher than $50 \mathrm{~mm}$ on average. Although the DDPT values of some areas were lower than $50 \mathrm{~mm}$ that is recognized as the warning threshold of precipitation in China, they had a strong chance of causing disasters. Hence, the regional rainstorm and flood disasters early warning system should be combined with the actual precipitation conditions of a region based on the national precipitation classification standards.

Overall, unlike the traditional perspective, this study offers a new way of thinking regarding extreme precipitation thresholds, which are called DDPTs in this study. Although there are some uncertainties about the DDPTs obtained, it provides a basis for further improving regionally differentiated disaster-triggering daily precipitation thresholds from the rainstorm and flood disaster perspective.

Author Contributions: W.L. and J.W. conceived and designed the study; J.Y. validated the data; W.L. and R.T. analyzed the data; W.L. and J.W. wrote the paper; W.L., J.W. and M.Y. revised the manuscript. All authors have read and agreed to the published version of the manuscript.

Funding: This study was financially supported by the National Key Research and Development Program, grant number 2016YFA0602403, and the National Natural Science Foundation of China, grant number 41571492.

Acknowledgments: The authors would like to acknowledge valuable comments by the three anonymous reviewers on an earlier version of this manuscript.

Conflicts of Interest: The authors declare no conflict of interest. 


\section{References}

1. Dankers, R.; Arnell, N.W.; Clark, D.B.; Falloon, P.D.; Fekete, B.M.; Gosling, S.N.; Heinke, J.; Kim, H.; Masaki, Y.; Satoh, Y.; et al. First look at changes in flood hazard in the Inter-Sectoral Impact Model Intercomparison Project ensemble. Proc. Natl. Acad. Sci. USA 2014, 111, 3257-3261. [CrossRef] [PubMed]

2. Pielke, J.; Downton, M.W. Precipitation and damaging floods: Trends in the United States, 1932-1997. J. Clim. 2000, 13, 3625-3637. [CrossRef]

3. Li, J.; Wang, B. Predictability of summer extreme precipitation days over eastern China. Clim. Dyn. 2018, 51, 4543-4554. [CrossRef]

4. Tang, R.; Wu, J.; Ye, M.; Liu, W. Impact of Economic Development Levels and Disaster Types on the Short-Term Macroeconomic Consequences of Natural Hazard-Induced Disasters in China. Int. J. Disaster Risk Sci. 2019, 10, 371-385. [CrossRef]

5. Liu, J.; Hertel, T.W.; Diffenbaugh, N.S.; Delgado, M.S.; Ashfaq, M. Future property damage from flooding: Sensitivities to economy and climate change. Clim. Chang. 2015, 132, 741-749. [CrossRef]

6. Jongman, B.; Hochrainer-Stigler, S.; Feyen, L.; Aerts, J.; Mechler, R.; Botzen, W.J.; Bouwer, L.M.; Pflug, G.; Rojas, R.; Ward, P.J. Increasing stress on disaster-risk finance due to large floods. Nat. Clim. Chang. 2014, 4, 264-268. [CrossRef]

7. Zhou, Q.; Leng, G.; Feng, L. Predictability of state-level flood damage in the conterminous United States: The role of hazard, exposure and vulnerability. Sci. Rep. 2017, 7, 5354. [CrossRef]

8. Xu, Z.; Fan, K.; Wang, H.J. Decadal variation of summer precipitation over China and associated atmospheric circulation after the late 1990s. J. Clim. 2015, 28, 4086-4106. [CrossRef]

9. Ma, S.; Zhou, T.; Dai, A.; Han, Z. Observed changes in the distributions of daily precipitation frequency and amount over China from 1960 to 2013. J. Clim. 2015, 28, 6960-6978. [CrossRef]

10. Ren, G.Y.; Feng, G.; Yan, Z.W. Progresses in Observation Studies of Climate Extremes and Changes in the mainland of China. Clim. Environ. Res. 2010, 15, 337-353. (In Chinese)

11. Wu, W.; You, Q.; Wang, D. Characteristics of Extreme Precipitation in China Based on Homogenized Precipitation Data. J. Nat. Res. 2016, 31, 1015-1026. (In Chinese)

12. Qiu, H.; Cao, M.; Hu, S. The relationship between the frequency and the scale of flood situation in China from 1950 to 2010. J. Nat. Disaster 2013, 22, 114-119. (In Chinese)

13. Yin, Z.; Tian, P.; Chi, X. Multi-scenario-based risk analysis of precipitation extremes in China during the past 60 years (1951-2011). Acta Geogr. Sin. 2018, 73, 405-413. (In Chinese)

14. Kong, F.; Shi, P.J.; Fang, J. Advances and Prospects of Spatiotemporal Pattern Variation of Extreme Precipitation and its Affecting Factors under the Background of Global Climate Change. J. Catastrophol. 2017, 32, 165-174. (In Chinese)

15. Anagnostopoulou, C.; Tolika, K. Extreme precipitation in Europe: Statistical threshold selection based on climatological criteria. Theor. Appl. Climatol. 2012, 107, 479-489. [CrossRef]

16. Chi, X.; Yin, Z.; Wang, X.; Sun, Y. A comparison of methods for benchmarking the threshold of daily precipitation extremes in China. J. Catastrophol. 2015, 30, 186-190. (In Chinese)

17. Hu, K.; Ivanov, P.C.; Chen, Z.; Carpena, P.; Stanley, H.E. Effect of trends on detrended fluctuation analysis. Phys. Rev. E 2001, 64, 011114. [CrossRef]

18. Zhang, Q.; Zhang, J.; Yan, D.; Wang, Y. Extreme precipitation events identified using detrended fluctuation analysis (DFA) in Anhui, China. Theor. Appl. Climatol. 2014, 117, 169-174. [CrossRef]

19. He, S.; Yang, J.; Bao, Q.; Wang, L.; Wang, B. Fidelity of the Observational/Reanalysis Datasets and Global Climate Models in Representation of Extreme Precipitation in East China. J. Clim. 2019, 32, $195-212$. [CrossRef]

20. Plummer, N.; Salinger, M.J.; Nicholls, N.; Suppiah, R.; Hennessy, K.J.; Leighton, R.M.; Trewin, B.; Page, C.M.; Lough, J.M. Changes in Climate Extremes over the Australian Region and New Zealand During the Twentieth Century. Clim. Chang. 1999, 42, 183-202. [CrossRef]

21. Santos, C.; Ghelli, A. Observational probability method to assess ensemble precipitation forecasts. Q. J. R. Meteorol. Soc. 2012, 138, 209-221. [CrossRef]

22. Liu, B.; Chen, X.; Chen, J.; Chen, X. Impacts of different threshold definition methods on analyzing temporal-spatial features of extreme precipitation in the Pearl River Basin. Stoch. Environ. Res. Risk Assess. 2017, 31, 1241-1252. [CrossRef] 
23. Schär, C.; Ban, N.; Fischer, E.M.; Rajczak, J.; Schmidli, J.; Frei, C.; Giorgi, F.; Karl, T.R.; Kendon, E.J.; Klein, A.M.G.; et al. Percentile indices for assessing changes in heavy precipitation events. Clim. Chang. 2016, 137, 201-216. [CrossRef]

24. Zhai, P.; Zhang, X.; Wan, H.; Pan, X. Trends in total precipitation and frequency of daily precipitation extremes over China. J. Clim. 2005, 18, 1096-1108. [CrossRef]

25. Beniston, M.; Stephenson, D.B.; Christensen, O.B.; Ferro, C.; Frei, C.; Halnaes, G.K.; Holt, T.; Julhä, K.; Koffi, B.; Palutikof, J.; et al. Future extreme events in European climate: An exploration of regional climate model projections. Clim. Chang. 2007, 81, 71-95. [CrossRef]

26. Mekasha, A.; Tesfaye, K.; Duncan, A.J. Trends in daily observed temperature and precipitation extremes over three Ethiopian eco-environments. Int. J. Climatol. 2014, 34, 1990-1999. [CrossRef]

27. Li, F.; Collins, W.D.; Wehner, M.F.; Williamson, D.L.; Olson, J.G.; Algieri, C. Impact of horizontal resolution on simulation of precipitation extremes in an aqua-planet version of Community Atmospheric Model (CAM3). Tellus Ser. A Dyn. Meteorol. Oceanogr. 2011, 63, 884-892. [CrossRef]

28. Palmer, T.N.; Räisänen, J. Quantifying the risk of extreme seasonal precipitation events in a changing climate. Nature 2002, 415, 512. [CrossRef]

29. Kharin, V.V.; Zwiers, F.W.; Zhang, X.; Wehner, M. Changes in temperature and precipitation extremes in the CMIP5 ensemble. Clim. Chang. 2013, 119, 345-357. [CrossRef]

30. Shi, P.J. Disaster Risk Science, 2nd ed.; Springer: New York, NY, USA, 2019.

31. Gao, C.; Zhang, Z.; Zhai, J.; Liu, Q.; Yao, M. Research on meteorological thresholds of drought and flood disaster: A case study in the Huai River Basin, China. Stoch. Environ. Res. Risk Assess. 2015, 29, 157-167. [CrossRef]

32. Yang, L. Climate Change of Extreme Precipitation in Xinjiang. Acta Geogr. Sin. 2010, 58, 577-583. (In Chinese)

33. Min, S.; Qian, Y. Regionality and persistence of extreme precipitation events in China. Adv. Water Sci. 2008, 19, 763-771. (In Chinese)

34. Huang, J.; Wei, W.; Yang, Q.; Yao, J. Variation Tendency and Characteristics of Extreme Precipitation on the Southern Edge of the Taklimakan Desert. Desert Oasis Meteorol. 2012, 6, 30-34. (In Chinese)

35. Li, Z.; Zheng, F.; Liu, W.; Flanagan, D. Spatial distribution and temporal trends of extreme temperature and precipitation events on the Loess Plateau of China during 1961-2007. Quat. Int. 2010, 226, 92-100. [CrossRef]

36. Li, X.; Jiang, F.; Li, L.; Wang, G. Spatial and temporal variability of precipitation concentration index, concentration degree and concentration period in Xinjiang, China. Int. J. Climatol. 2011, 31, 1679-1693. [CrossRef]

37. Tang, Y.H.; Chen, X.H. Multi-scale Spatio-temporal Characteristics and Influence of Precipitation Variation in Zhujiang River Basin During the Last 50 Years. Sci. Geogr. Sin. 2015, 35, 282-287. (In Chinese)

38. Wu, J.; Gao, X.J. A gridded daily observation dataset over China region and comparison with the other datasets. Chin. J. Geophys. 2013, 56, 1102-1111. (In Chinese)

39. Xu, L.; Wang, A. Application of the Bias Correction and Spatial Downscaling algorithm on the temperature extremes from CMIP5 multi-model ensembles in China. Earth Space Sci. 2019. [CrossRef]

40. Liu, L.; Ning, L.; Liu, J.; Yan, M.; Sun, W.Y. Prediction of summer extreme precipitation over the middle and lower reaches of the Yangtze River basin. Int. J. Climatol. 2019, 39, 375-383. [CrossRef]

41. Han, Z.; Zhou, T. Assessing the quality of APHRODITE high-resolution daily precipitation dataset over contiguous China. Chin. J. Atmos. Sci. 2012, 36, 361-373. (In Chinese)

42. Liu, M.; Xu, X.; Sun, A.Y.; Wang, K.; Liu, W.; Zhang, X. Is southwestern China experiencing more frequent precipitation extremes? Environ. Res. Lett. 2014, 9, 064002. [CrossRef]

43. CMA. Yearbook of Meteorological Disasters of China; China Meteorological Press: Beijing, China, 2012; pp. 181-186. (In Chinese)

44. Wu, J.; Han, G.; Zhou, H.; Li, N. Economic development and declining vulnerability to climate-related disasters in China. Environ. Res. Lett. 2018, 13, 034013. [CrossRef]

45. Wu, J.; Li, Y.; Li, N.; Shi, P. Development of an asset value map for disaster risk assessment in China by spatial disaggregation using ancillary remote sensing data. Risk Anal. 2018, 38, 17-30. [CrossRef] [PubMed]

46. Wu, J.; Ye, M.; Wang, X.; Koks, E. Building Asset Value Mapping in Support of Flood Risk Assessments: A Case Study of Shanghai, China. Sustainability 2019, 11, 971. [CrossRef]

47. Ye, M.; Wu, J.; Wang, C.; He, X. Historical and future changes in asset value and GDP in areas exposed to tropical cyclones in China. Weather Clim. Soc. 2019, 11, 307-319. [CrossRef] 
48. Wu, J.; Li, Y.; Shi, P. Benchmark wealth capital stock estimations across China's 344 prefectures: 1978 to 2012. China Econ. Rev. 2014, 31, 288-302. [CrossRef]

49. Qi, W.; Liu, S.; Zhao, M.; Liu, Z. China's different spatial patterns of population growth based on the "Hu Line". J. Geogr. Sci. 2016, 26, 1611-1625. [CrossRef]

50. Ye, D. Symmetry distribution of cities in China. Sci. China Ser. D Earth Sci. 2001, 44, 716-725. [CrossRef]

51. Wang, J.; Chen, C.; Liu, Y.; Long, K.; Wang, C. Statistical Analysis of Persistent Heavy Rainfall in Sichuan. Meteorol. Sci. Technol. 2017, 45, 331-341. (In Chinese)

52. Bai, X.; Chen, J.; Shi, P. Landscape urbanization and economic growth in China: Positive feedbacks and sustainability dilemmas. Environ. Sci. Technol. 2011, 46, 132-139. [CrossRef]

53. Chen, J.; Liu, L. Characteristics of urban rainstorm and its disaster cause over Beijing in flood season of 2011. Torrential Rain Disasters 2011, 30, 282-287. (In Chinese)

(C) 2020 by the authors. Licensee MDPI, Basel, Switzerland. This article is an open access article distributed under the terms and conditions of the Creative Commons Attribution (CC BY) license (http://creativecommons.org/licenses/by/4.0/). 